\title{
Objective structured clinical examination versus traditional clinical examination among nursing students: A comparative approach
}

\author{
Hoda Mohamed Nafee ${ }^{* 1}$, Awatef El-Sayed Ahmed ${ }^{2}$, Ahlam Mohamed Hussien ${ }^{1}$ \\ ${ }^{1}$ College of Nursing, El-Mansoura University, Egypt \\ ${ }^{2}$ College of Nursing, Imam Abdulrahman Bin Faisal University, Egypt
}

Received: June 24, 2018

DOI: $10.5430 /$ jnep.v9n2p42
Accepted: September 16, $2018 \quad$ Online Published: September 30, 2018

URL: https://doi.org/10.5430/jnep.v9n2p42

\begin{abstract}
The complex nature of clinical competence in nursing consequently poses a challenge in identifying suitable assessment methods that are able to measure all its attributes as well as maintaining reliability, validity and objectivity. So the aim of this study was to compare nursing students' opinions, feedback and clinical achievements grades in the Objective Structured Clinical Examination (OSCE) and the Traditional Clinical Examination (TCE) methods. A descriptive research design was used to conduct the study at college of nursing -Immam Abdulrahman Bin Faisal University (IABU), kingdom of Saudi Arabia. A total of 96 undergraduate student nurses enrolled in the pediatric nursing course equally were divided randomly into TCE and OSCE group $(n=48)$ in each group. Two tools were used, first tool was a structured questionnaire form to collect data related student's academic number, age, method of exam used, achievement grades in the exam and the overall suggestions to improve the method of exam used where the second tool was a self-administered questionnaire that modified from a Pierre et al. (2004) OSCE feedback questionnaire which included 23 items and categorized under four main dimensions with 3-point Likert scale ranged from agree, neutral and disagree to evaluate students' opinions and feedback related to the quality, organization, scoring and physical set up of both methods. Results revealed that statistical significant differences were found with higher prevalence of agreement responses among students for OSCE methods related most of items listed in the four dimensions compared to those in TCE. Mean $\pm \mathrm{SD}$ total score of students' responses related to OSCE and TCE methods was $104.5 \pm 15.6$ and $95.3 \pm 17.5$ respectively where $p$ value $=$ .002. Majority of students $95.8 \%$ exposed to OSCE compared to $11.9 \%$ of them who exposed to the TCE achieved (A) excellent grades in the exam (score 90\%-100\%). Conclusion and recommendation, statistical significant differences were observed between students' opinion and feedback with high prevalence of agreement responses related to OSCE compared to TCE methods. Clinical achievement grade was high among students whom evaluated by OSCE compared to those evaluated by TCE method. The study recommended that OSCE must be used as an integral part of the under graduate nursing students' clinical assessment.
\end{abstract}

Key Words: Complex nature of clinical competence, Nursing students, Objective structured clinical examination, Traditional clinical examination

\section{INTRODUCTION}

The mainstream of patient care was provided by nurses, so they must be invested with good preparation to improve care and services in order to maintain quality of patient care. ${ }^{[1]}$
Clinical nursing education is a heart of the nurse's professional practice and is a critical to their education that provide students with the chance to translate theoretical knowledge into skills and enhancing their competencies in both nurs-

*Correspondence: Hoda Mohamed Nafee; Email: hmelsayed@iau.edu.sa; Address: College of Nursing, El-Mansoura University, Egypt. 
ing and clinical skills that required to give patient-centered care. ${ }^{[2]}$ For graduation there are a nursing curriculums that influenced bynursing requirements, the university and the faculty. Each university has courses such asislamic studies and english. Faculty requirements may include courses such as, chemistry, biology, nutrition, physics, and pharmacology. Nursing requirements include all essential courses to prepare students for the nursing profession and licensure which having a theoretical and clinical parts. ${ }^{[3,4]}$

Evidence shows that most of the newly graduated nurses have sufficient theoretical knowledge but they are not clinically proficient. According to the importance of clinical competency, the way of evaluation strategies should be assumed to determine the success rate of the clinical training, assess learning processes and the quality of teaching. ${ }^{[5]}$ One of the crucial components of learning and educational program isevaluationor examination. There are several means evaluating students' performance, one of them was the traditional evaluation that evaluate students' performance through multiple choice questions, written essay and or checklist that considered as subjective ways of evaluation, it not time consuming, not need extra staff or special preparation but has low degree of reliability and difficult standardization. Moreover, most of the trainees and students are not satisfied with the ways and the results of evaluation. ${ }^{[6,7]}$ Besides, traditional tests are summative and usually designed and administered by people outside the learning process which hardly know anything about what assessment should be achieved? It is more concerned with the provision of discriminative numerical marks, useless descriptions rather than the provision of formative feedback and tend to treat learners as powerless victims rather than active participants in the learning process in addition no fairness and not account for individual differences multiple intelligences/different learning styles. ${ }^{[8,9]}$

Any method for assessment of the clinical competences of students should have four criteria mainly those ofobjectivity,reliability, validity, and practicability. ${ }^{[10]}$ Now a day, the introduction of assessment methods that simulate practical clinical situations has provided a solution of low reliability and difficult standardization. The Objective Structured Clinical Examination (OSCE) that has been used in nursing education and other health care professions is defined as "the method of choice for evaluation of learner's clinical competences". [11]

OSCE was developed in the University of Dundee in the early 1970s and later introduced by Dr. Ronald Harden and his colleagues in 1975. It was described in detailafter some modification in 1979. ${ }^{[12-14]}$ OSCE wasreliable and valid and for assessing students' clinical performance, a multi-system

Published by Sciedu Press examination using real or simulated patients to evaluate the clinical skills and providing formative and summative evaluation. It has many advantages firstly asevaluation orjudgment of students' performance is made (summative) followed by the provision of feedback, from which the student can learn (formative), secondly, because each student is required to demonstrate specific behaviors in a simulated work environment, strict control over the clinical context is possible, while at the same time, reflecting real-life professional tasks. This control eliminates the "luck of the draw "problem" that arises when students are assessed within the "real-world "clinical environment"" with actual patients as well as the risk of harm occurring to a patient. ${ }^{[15,16]}$ In addition it is considered a true measure for essential clinical skills being evaluated, standardization, and not affected bysocial relationsor student's personality. ${ }^{[17]}$ OSCE is a safe practice to help students gain more confidence and competent when facinginstrumentsor the real patient in the hospital environment. ${ }^{[18]}$ The students' competencies are demonstrated in their knowledge, skills, interpersonal and communication skills, professionalism andpractice-based learning, as well as playing an important motivating role betweenteachers and the students to ensure the quality and appropriateness of a learning process. ${ }^{[19,20]}$ During the OSCE, students rotate around a circuit of at least 10 stations with adequate test length from 3 to 4 hours to obtain reliability, each station may allocated 10 minutes. ${ }^{[21,22]}$

The traditional format of clinical examination usually includes checklists and using for observation of students' performance inthe real clinical or the simulatedsituations. Proper selection of assessment methods can improve students' performance while faulty one can lead to erroneous decisions that might be deleterious to the future activities of the students. Thus assessment techniques appear to have an impact on learning strategies and to influence the performance of students. Nursing student's perception of the clinical competencies can be measured using a variety of methods likerecord of performance,essays, written case studies, dissimilar types of simulations, and objective structured clinical examination. ${ }^{[23]}$

\section{Aim of the study}

To compare nursing students' opinions, feedback and clinical achievements grades about OSCE and Traditional Clinical Examination (TCE) methods.

\section{METHOD}

\subsection{Research design}

A descriptive research design was used. 


\subsection{Research questions}

- Are there differences in the students' opinions and feedback related to OSCE and TCE methods?

- Are there differences in the formative academic clinical achievements grades among students exposed to the OSCE and those exposed to the TCE?

\subsection{Setting}

The study was conducted at the College of Nursing (IABU), kingdom of Saudi Arabia.

\subsection{Subjects}

All undergraduates fourth year female nursing students ( $\mathrm{n}=$ 96) enrolled in the pediatric nursing course, in the previous setting at the first semester academic year 2016-2017, their age ranged from 22-24 years old and they are exposed to OSCE before in other courses. They divided randomly into two groups (TCE was group 1and OSCE was group 2) using the systematic random sample technique, 48 students enrolled in each group, six students from group (1) withdrawn from the study according to their request to be 42 students who examined by the TCE and group (2) included 48 students who examined by OSCE method. The total number of the study subjects were 90 students.

\subsection{Tools of the study}

Two tools were used to collect the data. First tool was a structured questionnaire form which developed by the researchers after reviewing of literatures to collect data related to student'sacademic number, age, method of exam used, achievement grades in the exam and the overall suggestions to improve the method of exam used where the second tool was a self-administered questionnaire that modified from Pierre et al. (2004) $)^{[17]}$ OSCE feedback questionnaire which included 23 items instead of 32 items and categorized under four main dimensions with 3-point Likert scale ranged from agree, neutral and disagree and having a separate score.After this modification, the tool was revised by 5 experts in the field for content validity. The 1st section consists of 6 items and evaluates nursing students' opinions and feedback related to the quality of instructions \& organization of the exam, the 2 nd section have 8 items and looks at nursing students' opinions and feedback related of the quality of the exam performance, the 3 rd section have 5 items to investigate nursing students' opinions and feedback related the exam scoring objectivity and validity,and the 4 th section which have 4 items to identify nursing students'comments on the examination set-up.

\subsection{Ethical consideration}

A permission to conduct the study was obtained from the College Dean and a written informed consent was obtained from all participants after explanation of the study aim and procedure. Participants' reassured that the obtained data will be confidential and they have a right to withdraw from the study at any time without giving any reason.

\subsection{Validity}

Content validity of the tools was carried out by 5 experts in the nursing education field.

\subsection{Procedures}

A formative clinical evaluation for students enrolled in the pediatric nursing skills was planned from the start of the semester to be carried out using the two different methods of clinical examination to assess the students' opinion and feedback related to the methods used.

All students were informed from the start of the semester that a formative clinical evaluation (clinical screening) will be conducted in the mid of the semester and using two methods to assess the basic acquired pediatric nursing skills. The main intention of formative evaluation was to help students in development of knowledge and skills related to the pediatric nursing. With this category of evaluation, the instructors are able to identify the needs of the students and direct them to achieve their learning objectives and course educational goals.

Orientation for all students about the formative clinical examination OSCE and TCE methods nature, objectives, the process of application one day before the exam.

A pilot study was carried out on $5 \%$ of students to evaluate the clarity and applicability of the tool and modifications were done based on their responses. Students who participated in the pilot study were excluded from the study subjects.

The basic pediatric nursing skills need to be covered in the course were identified and applied for all students in the both groups. Procedures included in the students' formative evaluation were chest circumference measurement, infant's weight measurement, nasogastrictube insertion, jacket restraints, and instillation of ear drops, intramuscular injection, and assessment of the newborn. These procedures used to assess clinical competences of students.

The two different methods of examination were applied for one day in the skills labs affiliated to the college of nursing, IABU.

Students enrolled in group (1) were exposed to TCE, before starting the examination each procedure was named and recorded in a separate paper, three instructors were shared in this exam method and prepared three packages of models, 
equipments, supplies and checklists needed to all procedures as well as students registration sheet and answer sheets for the written questions. At the time of starting the examination, each student came to the examination lab and asked to pick 3 of the papers randomly, read it, and start to carry out the procedures in front of the instructor, the instructor observed student and gave her marks according previous performed checklists, the time of performing the procedure is changed according to the student's ability and the complexity of the technique. The maximum allowed time for each procedure was 15 minutes. Each student asked to answer three written short answer questions related to the procedure to assess her ability to integrate theory and practice.

All sheets and checklists were corrected by the assigned examiners and marked according student's answers and kept in separate file included all students' papers and the achievement grades in the exam.

Students enrolled in group (2) were exposed to the OSCE in 10 stations, 5 minutes was a time for each station. All required instructions for students and examiners were written in a format and with explicit marking criteria and distributed between students and examiners immediately before OSCE carried out.

Stations used in OSCE were the same seven procedures used in group (1) in addition to other three stations that assessed student's cognitive skills (photos for common congenital abnormalities among children, calculation of ORS and pediatric triage classification) using specific prepared sheets. Each student was carried out the procedures, assessed by examiners using the checklists in the skills labs and went through the same stations by moving around a series of stations every 5 minutes from one station to another to cover all stations and another 5 minutes to move between the stations, the total time to finish the OSCE was fifty five minutes. All sheets and checklists were corrected by the assigned examiners and marked according to the student's answers.

The total score of each station was modified to 10 marks. Sum of total exam marks for each students and the average was considered as 10 marks in both group and all students' paper of evaluation were kept in separate files.

A standardized technique of marking was used for students enrolled in the both groups, their performance was assessed by criterion reference for each step in the procedure checklist which scored 2 for done completely, 1 for done incompletely and 0 for not done.

Student's clinical achievement grades in the two groups was determined as in IABU policy:

- $90 \%$ to $100 \%$ considered as A = Excellent;
- $80 \%$ to $<90 \%$ considered as B = Very good;

- $70 \%$ to $<80 \%$ considered as $\mathrm{C}=$ Good;

- $60 \%$ to $<70 \%$ considered as D = Pass;

- Less than $60 \%$ of the total considered as F = Not pass or failed.

At the end of the exam, tools of the study were distributed to all students enrolled in both groups; they asked to fill it and write their opinions and feedback within 20-30 minutes. All sheets were collected by the clinical instructors shared in each exam method.

Students' files were completed and submitted to the course coordinator in the day of the exam and feedback was provided by the examiners individually for each student about her performance and achievement grades in both groups.

\subsection{Statistical analysis}

Data entry and statistical analysis were done using SPSS ver. 22.0 statistical software packages. Data were presented using descriptive statistics in the form of frequencies and percentages for the qualitative variables, mean and standard deviations for the quantitative variables. Mann-Whitney U test was used. Statistical significance was considered at $p$ value $<.05$

\section{Results}

Table 1 demonstrates comparison between nursing students' opinions related to TCE and OSCE instructions \& organization. A statistical significant difference was found with higher prevalence of agreement responses for OSCE methods related items of the exam was well organized-the exam was well structured-fully aware of the exam nature and method than TCE. Regarding well administration of the exam $88.1 \%$ in TCE compared to $82.6 \%$ of students in OSCE group ( $p=$ $.003)$.

Table 2 shows comparison between nursing students' feedback about the quality of the TCE and the OSCE performance. It was observed that $83.3 \%$ of the students in both groups were agreed that they aware of the level of information asked. Regarding the agreements of students in OSCE group related to items of wide range of clinical skills are covered, allow compensation of student's weakness in other areas, exam highlighted the area of weakness, relevancy of the tasks and provided opportunity to learn were higher $(95.9 \%, 83.4 \%, 85.4 \%, 93.7 \%$ and $89.6 \%)$ compared to those in the TCE $(90.4 \%, 76.2 \%, 78.6 \%, 78.6 \%$ and $88.1 \%$ respectively). Most of students in OSCE group (89.6\%) mentioned that the exam was less stress compared with $47.6 \%$ of those in TCE group. A statistical significant difference was found between the two groups of students responses $(p=.002)$. 
Table 1. Comparison between nursing students' opinions related to TCE and OSCE instructions \& organization

\begin{tabular}{|c|c|c|c|c|c|c|}
\hline \multirow{3}{*}{ Items } & \multicolumn{6}{|c|}{ Students’ Response } \\
\hline & \multicolumn{3}{|c|}{ TCE $(\mathrm{N}=42)$} & \multicolumn{3}{|c|}{$\operatorname{OSCE}(\mathrm{N}=48)$} \\
\hline & $\begin{array}{l}\text { Agree } \\
\text { No (\%) }\end{array}$ & $\begin{array}{l}\text { Neutral } \\
\text { No }(\%)\end{array}$ & $\begin{array}{l}\text { Disagree } \\
\text { No }(\%)\end{array}$ & $\begin{array}{l}\text { Agree } \\
\text { No }(\%)\end{array}$ & $\begin{array}{l}\text { Neutral } \\
\text { No }(\%)\end{array}$ & $\begin{array}{l}\text { Disagree } \\
\text { No }(\%)\end{array}$ \\
\hline The exam was well organized. & $33(78.6 \%)$ & $5(11.9 \%)$ & $4(9.5 \%)$ & $45(93.7 \%)$ & $2(4.2 \%)$ & $1(2.1 \%)$ \\
\hline The exam was well structured. & $34(79.8 \%)$ & $6(14.3 \%)$ & $2(4.8 \%)$ & $45(93.7 \%)$ & $1(2.1 \%)$ & $2(4.2 \%)$ \\
\hline $\begin{array}{l}\text { Instructions were adequate, clear and } \\
\text { unambiguous. }\end{array}$ & 37 (88.1\%) & $4(9.5 \%)$ & $1(2.4 \%)$ & $41(85.4 \%)$ & $6(12.5 \%)$ & $1(2.1 \%)$ \\
\hline Fully aware of the exam nature and method. & $32(76.2 \%)$ & $5(11.9 \%)$ & $5(11.9 \%)$ & $41(85.4 \%)$ & $4(8.3 \%)$ & $3(6.3 \%)$ \\
\hline $\begin{array}{l}\text { The time allocated for each procedure was } \\
\text { adequate. }\end{array}$ & $25(59.5 \%)$ & $3(7.1 \%)$ & $14(34.4 \%)$ & $41(85.4 \%)$ & $5(10.6 \%)$ & $2(4.2 \%)$ \\
\hline Generally the exam was well administered. & 37 (88.1\%) & $3(7.1 \%)$ & $2(4.8 \%)$ & $39(82.6 \%)$ & $5(10.9 \%)$ & $4(8.3 \%)$ \\
\hline Maximum score $=30$ & \multicolumn{3}{|c|}{$\begin{array}{l}\text { Median (IQR) } \\
24.5(9.00)\end{array}$} & \multicolumn{3}{|c|}{$\begin{array}{l}\text { Median (IQR) } \\
30.0(3.75)\end{array}$} \\
\hline$p$ Value $=.003^{*}$ & & & & & & \\
\hline
\end{tabular}

Table 2. Comparison between nursing students' feedback about the quality of the TCE and the OSCE performance

\begin{tabular}{|c|c|c|c|c|c|c|}
\hline \multirow{3}{*}{ Items } & \multicolumn{6}{|c|}{ Students' Response } \\
\hline & \multicolumn{3}{|l|}{ TCE N = 42} & \multicolumn{3}{|l|}{ OSCE $N=48$} \\
\hline & $\begin{array}{l}\text { Agree } \\
\text { No (\%) }\end{array}$ & $\begin{array}{l}\text { Neutral } \\
\text { No }(\%)\end{array}$ & $\begin{array}{l}\text { Disagree } \\
\text { No (\%) }\end{array}$ & $\begin{array}{l}\text { Agree } \\
\text { No (\%) }\end{array}$ & $\begin{array}{l}\text { Neutral } \\
\text { No (\%) }\end{array}$ & $\begin{array}{l}\text { Disagree } \\
\text { No }(\%)\end{array}$ \\
\hline $\begin{array}{l}\text { Wide ranges of clinical skills are } \\
\text { covered. }\end{array}$ & 38 (90.4\%) & $3(7.1 \%)$ & $1(2.4 \%)$ & $46(95.9 \%)$ & $2(4.2 \%)$ & 0 \\
\hline The exam was less stressful. & $20(47.6 \%)$ & $10(23.8 \%)$ & $12(28.6 \%)$ & $43(89.6 \%)$ & $5(10.4 \%)$ & 0 \\
\hline $\begin{array}{l}\text { Allowed student to compensate in } \\
\text { other areas. }\end{array}$ & $32(76.2 \%)$ & $8(19.0 \%)$ & $2(4.8 \%)$ & $40(83.4 \%)$ & $7(14.6 \%)$ & $1(2.1 \%)$ \\
\hline $\begin{array}{l}\text { The exam was highlighted areas of } \\
\text { weaknesses. }\end{array}$ & 33 (78.6\%) & $4(9.5 \%)$ & $5(11.9 \%)$ & $41(85.4 \%)$ & $3(6.2 \%)$ & $4(8.3 \%)$ \\
\hline $\begin{array}{l}\text { Students were aware of the level of } \\
\text { information asked. }\end{array}$ & 35 (83.4\%) & $3(7.1 \%)$ & $4(9.5 \%)$ & $40(83.3 \%)$ & $5(10.4 \%)$ & $3(6.4 \%)$ \\
\hline Tasks had clinical relevance. & $36(85.7 \%)$ & $3(7.1 \%)$ & $3(7.1 \%)$ & 45 (93.7\%) & $2(4.2 \%)$ & $1(2.1 \%)$ \\
\hline $\begin{array}{l}\text { The exam was provided } \\
\text { opportunities to learn. }\end{array}$ & 37 (88.1\%) & $4(9.5 \%)$ & $1(2.4 \%)$ & $43(89.6 \%)$ & $5(10.4 \%)$ & 0 \\
\hline $\begin{array}{l}\text { Tasks asked to perform were } \\
\text { consistent with teaching objectives. }\end{array}$ & 37 (88.1\%) & $4(9.5 \%)$ & $1(2.4 \%)$ & $41(85.4 \%)$ & $3(6.4 \%)$ & $4(8.3 \%)$ \\
\hline \multirow{2}{*}{ Maximum score $=40$} & \multirow{2}{*}{\multicolumn{3}{|c|}{$\begin{array}{l}\text { Median (IQR) } \\
32.0(8.5)\end{array}$}} & \multirow{2}{*}{\multicolumn{3}{|c|}{$\begin{array}{l}\text { Median (IQR) } \\
39.0(5.75)\end{array}$}} \\
\hline & & & & & & \\
\hline \multicolumn{7}{|l|}{$p$ Value $=.002^{*}$} \\
\hline
\end{tabular}

Table 3 notes comparison between nursing students' opinions related to the validity of the TCE and OSCE scoring. Response of students in the OSCE group was significantly higher than those in the TCE group related all items in Table 3 , it ranged between $87.5 \%$ to $83.3 \%$ compared to $80.9 \%$ to $73.8 \%$ respectively $(p=.004)$.

Table 4 demonstratescomparison between nursing students' feedback related to TCE and OSCE physical set-up. A significantly higher percentages of agreement response was observed from students in OSCE group related items of the environment was noise free, enough light and exam was wellstructured that ranged between $95.9 \%$ to $89.6 \%$ than those in TCE which ranged between $92.8 \%$ to $85.7 \%$ where $p$ value $=.053$. 
Table 3. Comparison between nursing students' opinions related to the validity of the TCE and OSCE scoring

\begin{tabular}{|c|c|c|c|c|c|c|}
\hline \multirow{3}{*}{ Items } & \multicolumn{6}{|c|}{ Students' Response } \\
\hline & \multicolumn{3}{|c|}{ TCE $(\mathrm{N}=42)$} & \multicolumn{3}{|c|}{ OSCE $(\mathrm{N}=48)$} \\
\hline & $\begin{array}{l}\text { Agree } \\
\text { No }(\%) \\
\end{array}$ & $\begin{array}{l}\text { Neutral } \\
\text { No }(\%)\end{array}$ & $\begin{array}{l}\text { Disagree } \\
\text { No }(\%)\end{array}$ & $\begin{array}{l}\text { Agree } \\
\text { No (\%) } \\
\end{array}$ & $\begin{array}{l}\text { Neutral } \\
\text { No }(\%)\end{array}$ & $\begin{array}{l}\text { Disagree } \\
\text { No }(\%)\end{array}$ \\
\hline The exam was fair in testing knowledge and skills. & $34(80.9 \%)$ & $2(4.8 \%)$ & $3(7.2 \%)$ & $41(85.4 \%)$ & $5(10.4 \%)$ & $2(4.2 \%)$ \\
\hline $\begin{array}{l}\text { The exam was minimized the chance of failure in the } \\
\text { exam as compared to other test formats. }\end{array}$ & $33(78.6 \%)$ & $7(16.7 \%)$ & $2(4.8 \%)$ & $42(87.5 \%)$ & $5(10.4 \%)$ & $1(2.1 \%)$ \\
\hline $\begin{array}{l}\text { The exam scores reflect individual performance at the } \\
\text { exam. }\end{array}$ & $34(80.9 \%)$ & $4(9.5 \%)$ & $4(9.5 \%)$ & $41(85.4 \%)$ & $4(8.3 \%)$ & $3(6.3 \%)$ \\
\hline $\begin{array}{l}\text { The scores provide true measure of essential clinical } \\
\text { skills. }\end{array}$ & $31(73.8 \%)$ & $7(16.7 \%)$ & $4(9.5 \%)$ & $40(83.3 \%)$ & $5(10.4 \%)$ & $3(6.3 \%)$ \\
\hline $\begin{array}{l}\text { Personality and social relations of students do not affect } \\
\text { the exam scores. }\end{array}$ & $34(80.9 \%)$ & $6(14.3 \%)$ & $2(4.8 \%)$ & $40(83.3 \%)$ & $5(10.4 \%)$ & $3(6.3 \%)$ \\
\hline Maximum score $=25$ & \multicolumn{3}{|c|}{$\begin{array}{l}\text { Median (IQR) } \\
20.5(4.3)\end{array}$} & \multicolumn{3}{|c|}{$\begin{array}{l}\text { Median (IQR) } \\
25.0(5.0)\end{array}$} \\
\hline$p$ value $=.004^{*}$ & & & & & & \\
\hline
\end{tabular}

*Statistically significant difference using Mann-Whitney U test

Table 4. Comparison between nursing students' feedback related to TCE and OSCE physical set-up

\begin{tabular}{|c|c|c|c|c|c|c|}
\hline \multirow{3}{*}{ Items } & \multicolumn{6}{|c|}{ Students’ Response } \\
\hline & \multicolumn{3}{|l|}{ TCE $(N=42)$} & \multicolumn{3}{|c|}{ OSCE $(N=48)$} \\
\hline & $\begin{array}{l}\text { Agree } \\
\text { No (\%) }\end{array}$ & $\begin{array}{l}\text { Neutral } \\
\text { No (\%) }\end{array}$ & $\begin{array}{l}\text { Disagree } \\
\text { No (\%) }\end{array}$ & $\begin{array}{l}\text { Agree } \\
\text { No (\%) }\end{array}$ & $\begin{array}{l}\text { Neutral } \\
\text { No (\%) }\end{array}$ & $\begin{array}{l}\text { Disagree } \\
\text { No (\%) }\end{array}$ \\
\hline Adequate space was provided. & $39(92.8 \%)$ & $2(4.8 \%)$ & $1(2.4 \%)$ & $43(89.6 \%)$ & $4(8.3 \%)$ & $1(2.1 \%)$ \\
\hline Environment was noise free. & $32(76.2 \%)$ & 7 (16.7\%) & $3(7.2 \%)$ & $43(89.6 \%)$ & $5(10.4 \%)$ & 0 \\
\hline Enough lighting. & 39 (92.8\%) & $2(4.8 \%)$ & $1(2.4 \%)$ & 46 (95.9\%) & $2(4.2 \%)$ & 0 \\
\hline Exam was well-structured. & $36(85.7 \%)$ & $4(9.5 \%)$ & $2(4.8 \%)$ & 45 (93.8\%) & $3(6.2 \%)$ & 0 \\
\hline Maximum score $=20$ & $\begin{array}{l}\text { Median (IQR } \\
18.5(4.00)\end{array}$ & & & $\begin{array}{l}\text { Median (IQ1 } \\
20.0(1.75)\end{array}$ & & \\
\hline$p$ value $=.053^{*}$ & & & & & & \\
\hline
\end{tabular}

*Statistically significant difference using Mann-Whitney U test

Table 5 illustrates comparison between the total score of total score of students' responses with higher rate among students' responses related to TCE and OSCE methods. A students in the OSCE group than others (mean \pm SD 104.5 statistically significant difference was found between the \pm 15.6 and $95.3 \pm 17.5$ respectively) where $p$ value $=.002$.

Table 5. Comparison between the total score of students' responses related to TCE and OSCE methods

\begin{tabular}{lllll}
\hline Groups & Mean \pm SD & Median (IQR) & 95\% CI & p value \\
\hline $\begin{array}{l}\text { TCE }(\mathrm{N}=42) \\
\text { Maximum score } 115\end{array}$ & $95.3 \pm 17.5$ & $93.0(23.25)$ & 90.0 to 100.6 & $.002 *$ \\
\hline $\begin{array}{l}\text { OSCE }(\mathrm{N}=48) \\
\text { Maximum score } 115\end{array}$ & $104.5 \pm 15.6$ & $110.5(14.0)$ & 100.1 to 108.9 & \\
\hline
\end{tabular}

*Statistically significant by using Mann-Whitney U test

Figure 1 reflects comparison between students' opinions related to OSCE and TCE methods. More than 3/4 (77.1\%) of students in the OSCE group responded that the exam was good compared to $61.9 \%$ of them in TCE group.

Figure 2 illustrates comparison between students in the OSCE and TCE groups' achievement in the clinical exam.
Majority of students in OSCE group (95.8\%) got excellent (A) compared to only $11.9 \%$ of students in TCE.

Figure 3 shows that $19 \%$ of students in the OSCE group compared to $8.3 \%$ of those in the TCE group suggested that the procedures need more time to be applied. 


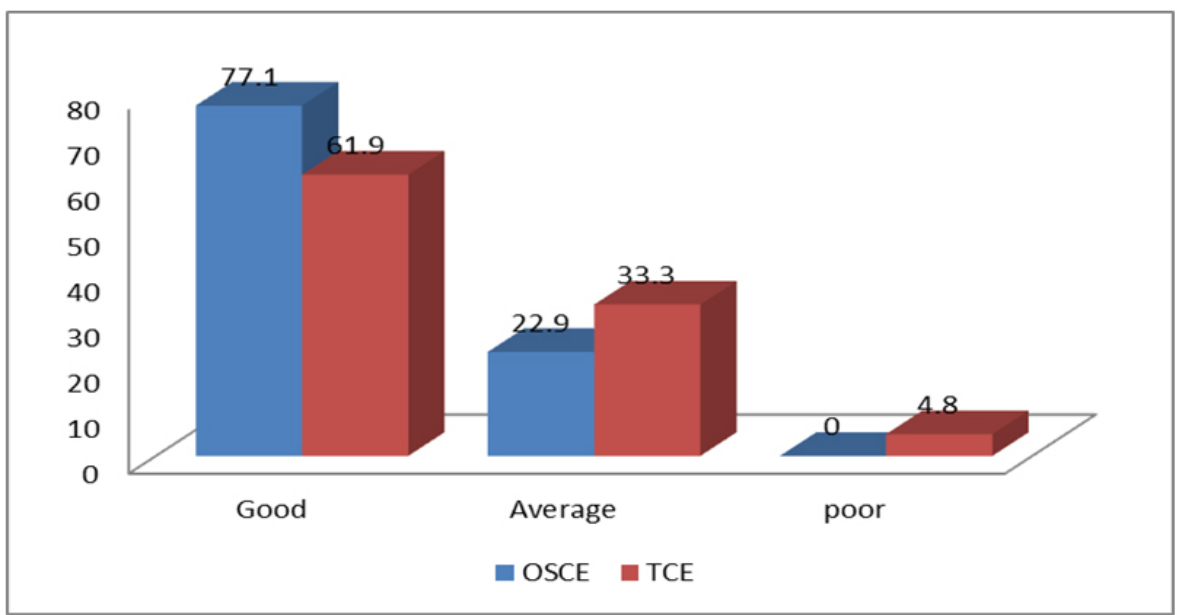

Figure 1. Comparison between students' opinions related to OSCE and TCE methods

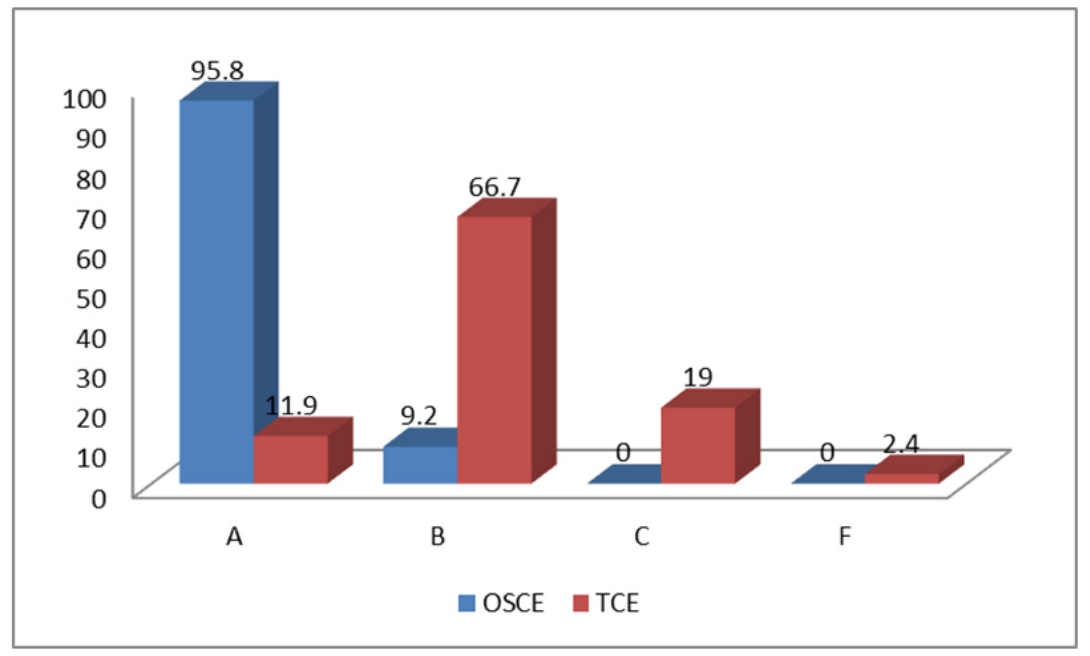

Figure 2. Comparison between students in the OSCE and TCE groups achievements in the clinical exam

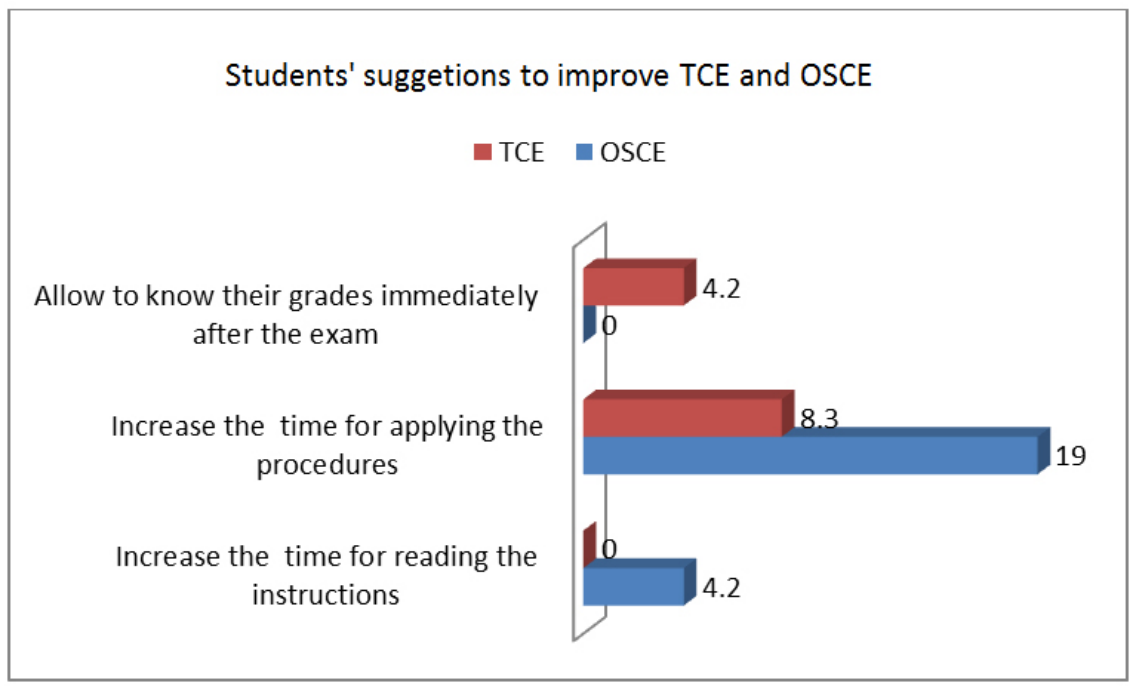

Figure 3. Comparison between students' suggestions to improve TCE and OSCE 


\section{Discussion}

The assessment of student's clinical competence is highly important, the OSCE is an approach to student assessment in which aspects of clinical competence are evaluated in a comprehensive, consistent and structured manner, with close attention to the objectivity of the process which reduced risk of examiner bias and provide discrimination between students level of performance. This is a comparative study was conducted to assess students' who exposed either TCE or OSCE their feedback, opinions and clinical achievement grades in the pediatric nursing course. Generally, results of the present study indicated that a statistically significant difference was found between mean total score of students responses with higher rate among students who exposed to OSCE than those who exposed to TCE methods (mean \pm SD $104.5 \pm 15.6$ and $95.3 \pm 17.5$ respectively) where $p$ value $=$ .002 as shown in Table 5.

As for instructions and organization of the exam, the current study pointed out that a higher median scores for responses of students who exposed to OSCE versus those exposed to TCE methods with statistical significant difference $(p=.003)$ (see Table 1). These results are in concurrent with those obtained by Eldarir and Hamid (2013) $)^{[14]}$ and Smith et al. (2012) ${ }^{[24]}$ who found that the mean score of students responses who undergone OSCE was high as compared to the group who undergone the TCE method. Majority of students (93.7\%) in OSCE group agreed that the exam was well organized and structured compared to $78.6 \%$ and $79.8 \%$ of them in TEC group. Those results are in the same line with Nemer \& Kandeel (2009). ${ }^{[25]}$ Also the present study revealed that above $85 \%$ of students in OSCE responded their agreement that instructions of the exam were adequate, clear and unambiguous. They are fully aware of the exam nature and method and the time allocated for each procedure was adequate compared to $88.1 \%, 76.2 \%$ and $59.5 \%$ of them in TCE group and those results are supported by Saed and Abbas (2017) ${ }^{[26]}$ who found that the majority of nursing students agreed that the OSCE exam instructions were adequate, opportunity for clarification, well-structured, organized, sequenced and time allocated was appropriate but disagree with Mahotra et al $(2013)^{[27]}$ studies that found $95 \%$ of students exposed to Objective Structured Practical Exam (OSPE stated that five minutes are not enough for each station), this may be the OSPE stations are different than OSCE stations.

In comparison between nursing students' feedback related the quality of TCE and OSCE performance (see Table 2), the current study revealed that majority of students in OSCE group agreed that the exam had wide ranges of clinical skills covered, this result is agreed with findings obtained by many

Published by Sciedu Press authors as Nazzawi (2018), ${ }^{[28]}$ Mitchell et al. (2009), ${ }^{[29]}$ Hasanet et al. (2012) $)^{[30]}$ and Vargas et al. (2007) ${ }^{[31]}$ who found that students who exposed to OSCE stated that the exam covers most of the objectives of their clinical rotation nevertheless, Mitchell et al. (2009) ${ }^{[32]}$ reported that contrary to various positive specification of OSCE, it is required to better assess clinical skills. More than three quarters of students in OSCE group reported that the exam is less stressful exam compared to less than half of them in TCE group. This may be due to students exposed to OSCE before in other courses during their study in the college, this result is in the harmony of those obtained by Chetna et al. (2016) ${ }^{[33]}$ study, they found that $51.25 \%$ of students exposed to OSCE and $33.75 \%$ of them exposed to TCE pointed that exam less stressful while disharmony found with Nazzawi (2018), ${ }^{[28]}$ Mater et al. (2014) ${ }^{[18]}$ and Ali et al. (2012) ${ }^{[34]}$ whom highlighted that the majority of the student reported OSCE was very stressful and can be a strong anxiety-producing experience. In addition the present study revealed that more than three quarters of students in both groups responded their agreement that they were aware of the level of information asked and tasks asked to perform were consistent with teaching objectives in the course, these results are concurrent with findings of Chetna et al. (2016) ${ }^{[33]}$ and Eldarir et al. (2013). ${ }^{[14]}$ Most of students exposed to OSCE compared to three quarters of them who exposed to TCE mentioned that exams allow students to compensate in other areas, this finding at the same line of El Nemer \& Kandeel (2009) ${ }^{[25]}$ whom found that students in OSCE group can compensate in some areas and minimized their chances of failing. As well as the current study found that most of students in OSCE group compared with three quarters of them in TCE agreed that the exam was highlighted areas of weaknesses in students and curriculum, this result is also supported by findings obtained by Goud et al. (2014) ${ }^{[37]}$ and Eldarir and Hamid (2013). ${ }^{[14]}$

In relation to nursing students' opinions concerning the exam scoring and validity, the present study indicated that higher percentages of students in OSCE group than those in TCE group pointed that the exam was, fair in testing knowledge and skills, minimize the chance of failure, reflect individual performance, provide true measure of essential clinical skills and personality and social relations of students do not affect the exam scores as shown in Table 3, these results are in agreement with those obtained by Mukwato et al. (2013), ${ }^{[21]}$ Eldarir and Abd Hamid (2013). ${ }^{[14]}$

Regarding nursing students' feedback related to the exam physical set-up, the current study illustrated that there is a significantly higher percentage of agreement response from students in OSCE group related items of the environment was 
noise free, enough light and exam was well-structured than those in TCE where $p=.053$ as shown in Table 4. These findings are in the same line with several studies reported that the criteria of a good examination include a relaxed environment Lakshmipathy (2015) ${ }^{[35]}$ and Abraham(2009). ${ }^{[36]}$

As for the comparison between students in the OSCE and TCE groups achievements in the clinical exam, the present study revealed that majority of students in OSCE group had excellent grade (A) which ranged between $90 \%-100 \%$ as followed by the university policy compared to those in the TCE. This result may be due to the OSCE exam have ability to evaluate a wide range of knowledge and skills and was developed to address the attitudinal and psychomotor skills that are required to perform in the clinical areas, whereas TCE method of exam assesses and evaluate limited areas of knowledge and focuses on cognitive and psychomotor skills. These findings are consistent with results obtained by Nasir et al. (2015), ${ }^{[38]}$ Eldarir and Hamid (2013) ${ }^{[14]}$ and Mondal et al. (2012) ${ }^{[39]}$ who found that the mean scores and GBA of students who undergone OSCE were high as compared to the group who undergone TCE method and they emphasized that the real power of OSCE lies in its ability to evaluate a wide range of knowledge and skills which improves the reliability of the examination, and provides an innovative learning experience for students. It offers a valid means to evaluate student's clinical performance in a holistic manner.

Concerning students' opinions related to OSCE and TCE methods, the current study revealed that more than three quarters of students who exposed to OSCE compared to less than two thirds of them who exposed to TCE viewed that the exam was good in their opinions (see Figure 1), this results in the harmony with Lohakare (2015) ${ }^{[40]}$ study who showed that the highest rate of satisfaction belonged to OSCE method in terms of course objectives, teaching level evaluation, increased decision-making ability than TCE method. Ali et al. $(2012)^{[34]}$ study found that $75.9 \%$ of students stated that OSCE has been a fair assessment tool, $72.4 \%$ of them mentioned it is comprehensive, $50 \%$ of them pointed that OSCE had clear instructions and $68.9 \%$ of them noted that it is minimized the chances of failing. The different studies used to support findings of the present study indicated that students' feedback confirmed their acceptance of OSCE as an evaluation tool for their clinical skills and majority of them were satisfied with organization and administration of the OSCE. Moreover, a recent study was conducted by Sony et al. $(2017)^{[41]}$ indicated that majority of students who exposed to OSCE and TCE methods showed positive opinions and acceptance related to their clinical skills' assessment.

In the present study, suggestion of OSCE students was reflected that time needed to applying the procedures must increase than the actual charted time and this result in agreement with Ameh et al. ${ }^{[42]}$ who said that, the insufficient time at OSCE station was one of students' complaints in some of the studies which investigated students' perspective of OSCE.

\section{Conclusion}

Based on findings that cited above, the present study concluded that the higher prevalence of agreement with statistically significant differences were found among students who exposed to OSCE than those exposed to TCE related to exam ,instructions , organization, quality, performance, validity of scoring, and the physical set-up. High percentages $95.8 \%$ of students who exposed to OSCE achieved (A) score in their exam compared $11.9 \%$ in TCE group. Regarding students' reflection about stations time $19.0 \%$ of students in the OSCE group compared to $8.3 \%$ of them in TCE group reflected that the time allowed for each station or procedure not enough and also $4.2 \%$ of students in group 2 (OSCE) recommended extra time for reading the instructions. Good exam was the opinions responded by $77.1 \%$ of students in OSCE compared to $61.9 \%$ of them in TCE group.

\subsection{Recommendations}

Based on findings of the current study, it was recommended that:

- It's important to use OSCE as an integral part of the under graduate nursing students' clinical assessment.

- It's better to evaluate the nursing student clinical achievement using a combination between OSCE and TCE methods.

- Weighing the time needed for the selected stations was the most important consideration with preparation of OSCE.

- The researchers suggest further studies to be conducted in this field on larger sample size.

\subsection{Limitations of the study}

Time consuming used in preparation of OSCE stations and its instruction as well as large number of instructors shared in the exam.

\section{CONFlicts OF InTEREST Disclosure}

The authors declare that there is no conflict of interest. 


\section{REFERENCES}

[1] Massey DL, Byrne JH, Higgins N, et al. Weeks Enhancing OSCE preparedness with video exemplars in undergraduate nursing students. A mixed method study. Nurse Educ Today. 2017; 54: 56-61.

[2] Al Mutair A. Clinical Nursing Teaching in Saudi Arabia Challenges and Suggested Solutions. J Nurs Care. 2015.

[3] El-Sanabary N. Women and the nursing profession in Saudi Arabia. In N. H. Bryant (Ed.), Women in nursing in Islamic societies. Pakistan: Oxford University Press; 2003.

[4] Tumulty G. Professional development of nursing in Saudi Arabia. Journal of Nursing Scholarship. 2001; 33(3): 285-290. https: //doi.org/10.1111/j.1547-5069.2001.00285.x

[5] Crisp N, Chen L. Global supply of health professionals. The New England Journal of Medicine. 2014; 370: 950-957. PMid:24597868 https://doi.org/10.1056/NEJMra1111610

[6] Rust C. The Impact of Assessment on Student Learning. Active Learning in Higher Education. 2002; 3(2): 145-158. https://doi. org/10.1177/1469787402003002004

[7] Siddiqui AU. Objective Structured Clinical Examination: a valid and reliable assessor of clinical competency. International Journal of Students' Research. 2011; 1: 72-75. https ://doi.org/10.5549/ IJSR. 1. 3.72-75

[8] Schuwirth L, Vander VC. ABC of learning and teaching in medicine: Written assessment. BMJ. 2003; 326(7390): 643-5. PMid:12649242 https://doi.org/10.1136/bmj .326.7390.643

[9] Mavis B, Henry R. Between a rock and a hard place: Finding a place for the OSCE in medical education. Med. Educ. 2002; 36(5): 408-9. PMid:12028388 https://doi.org/10.1046/j.1365-2923.20 $02.01241 . x$

[10] Kumari C, Yogesh K, Srinivasan P. Assess and Compare Objective Structured Clinical Examination (OSCE) Versus Traditional Clinical Examination (TCE) Regarding Denver Developmental Screening Test (DDST II) in Terms of Preference. International Journal of Health Sciences and Research (IJHSR). 2016; 6(7): 237-242.

[11] Al Saegh Maha AM, Almkhtar A. Perception of OSCE Examination in Iraqi Undergraduate Medical Students. Karbala J. Med. 2015; 8(1): 2056-2069.

[12] Harden R, Stevenson M, Downie W, et al. Assessment of clinical competence using an objective structured examination. Medical Education. 1975; 1447-451.

[13] Waterson T, Cater JI, Mitchell RG. An objective undergraduate clinical examination in child health. Arch Dis Child. 1980; 55: 917-922. https://doi.org/10.1136/adc.55.12.917

[14] Eldarir S, Hamid N, et al. Objective structured clinical evaluation versus traditional clinical achievement at maternity nursing. IOSR Journal of Dental and Medical Sciences. 2013; 4(3): 63-68. https://doi.org/10.9790/0853-0436368

[15] Bartfay WJ, Rombough R, Howse E, et al. The OSCE in nursing education: objective structured clinical examinations can be vehicles for nursing education and practice by promoting the mastery of clinical skills and decision making in controlled and safe environments. The Canadian Nurse. 2004; 100: 18-27.

[16] Major D. Seven years on the bandwagon: the progress of an objective structured clinical evaluation programme. Nurse Education Today. 2005; 25: 442-454. PMid:15982789 https://doi.org/10.1016/ j.nedt. 2005.03.010

[17] Pierre R, Wierenga A, Barton M, et al. Student Evaluation of an OSCE in Pediatric at the University of the West Indies, Jamaica. BMC Medical Education. 2004; 4(22): 1-7.

[18] Mater EAM, Ahmed EI, ElSayed AA, et al. The impact of the objective structured clinical examination approach for clinical evaluation skills on the student's performance in nursing college. World J Med Sci. 2014; 11(4): 609-613.

[19] Baid H. The objective structured clinical examination within intensive care nursing education. Nursing in Critical Care. 2011; 16(2): 99-105. PMid:21299763 https://doi .org/10.1111/j.1478-5 $153.2010 .00396 . x$

[20] MILLER GE, 2008 In John L, et al. Objective structured clinical exams: A critical review. Family Medicine. 2009; 574-578.

[21] Mukwato PK, Mwape L, Makukula MK, et al. Implementation of Objective Structured Clinical Examination for Assessing Nursing Students' Clinical Competencies: Lessons and Implications. Sci Res Journal. 2013; 4(10): 48-53.

[22] Idris AS, Hamza AA, Hafiz MM, et al. Teachers' and students' perceptions in surgical OSCE exam: A pilot study. Open Science Journal of Education. 2014; 2(1): 15-19.

[23] Mohammed L. Nursing students, perception towards the effectiveness of OSCE versus traditional method (case study) of clinical assessment. New Egyptian Journal of Medicine. 2011; 45: 33-35.

[24] Smith V, Muldoon K, Biesty L. The Objective Structured Clinical Examination (OSCE) as a strategy for assessing clinical competence in midwifery education in Ireland: A critical review. Nurse Education in Practice. 2012; 12(5): 242-247. PMid:22633118 https : //doi.org/10.1016/j.nepr.2012.04.012

[25] El-Nemer A, Kandeel N. Using OSCE as an Assessment Tool for Clinical Skills: Nursing Students' Feedback; AJBAS July September 2009; 2465-2472.

[26] Saed AM, Abbas NI. Feedback of under graduate nursing students about objective structured practical examination. Journal of Nursing Education and Practice. 2017; 7(3): 123-135. https://doi.org/ 10.5430/jnep.v7n3p68

[27] Mahotra S, Shah K, Patel V. Objective structured practical examination as a tool for the formative assessment of practice skills of under graduate students in pharmacology. Journal of Educ Health Promot. 2013; 2: 53. PMid:24251289 https://doi.org/10.4103/2277 $-9531.119040$

[28] Nazzawi AA. Dental Students' Perception of Objective Structured Clinical Evaluation. Journal of Tiba University Medical Sciences. 2018; 3(1): 64-69. https://doi.org/10.1016/j.jtumed. 201 7.09 .002

[29] Mitchell ML, Henderson A, Groves M, et al. The objective structured clinical examination (OSCE): Optimizing its value in the undergraduate nursing curriculum. Nurse Education Today. 2009.

[30] Hasan E, Ali L, Pasha A, et al. Association of the pre-internship objective structured clinical examination in final year medical students with comprehensive written examination. Med Educ Online. 2012; 17: 1-7.

[31] Vargas AL, Boulet JR, Errichetti A, et al. Developing performancebased medical school assessment programs in resource-limited environments. Med Teach. 2007; 29: 192-198. PMid:17701632 https : //doi.org/10.1080/01421590701316514

[32] Mitchell ML, et al. The objective structured clinical examination (OSCE) (2009): optimizing its value in the undergraduates nursing curriculum. Nurse Educ. Today. 2007; 29(4): 398-404.

[33] Chetna K, Yogesh K, Srinivasan P. Assess and Compare Objective Structured Clinical Examination (OSCE) Versus Traditional Clinical Examination (TCE) Regarding Denver Developmental Screening Test (DDST II) in Terms of Preference. International Journal of Health Sciences and Research. 2016; 6(7): 237-242.

[34] Ali G, Mehdi A, Ali H. Objective structured clinical examination (OSCE) as an assessment tool for clinical skills in Sohag University. Nursing students perspective. Journal of Environmental Studies. 2012; 8: 59-69. 
[35] Lakshmipathy K. MBBS student perceptions about physiology subject teaching and objective structured practical examination based formative assessment for improving competencies. Adv. Physio. Educ. 2015; 39: 198-204. PMid:26330038 https ://doi.org/10.1152/ advan.00073.2014

[36] Abraham R, Raghavendra R, Surekha K, et al. A trial of the objective structured practical examination in physiology at Melaka Manipal Medical College, India. Adv Physiol Educ. 2009; 33(1): 2123. PMid:19261756 https ://doi.org/10.1152/advan. 90108. 2008

[37] Goud BKM, Begum S, ZakinB, et al. Perceptions and performance of undergraduate medical students in objective structured practical examinations OSPE in Biochemistry at RAK Medical and Health Services University, UAE. Journal of Universal College of Medical Science. 2014; 2(8): 4.

[38] Nasir N, Asad M, Sami W, et al. Student's perception on objective structured practical examination in college of Applied Medical Sciences. International Journal of Advanced Research. 2015; 3(6): 535-540.
[39] Mondal R, Sarkar S, Nandi M, et al. Comparative analysis between OSCE and conventional evaluation as a formative evaluation tool in pediatrics for final MBBS students. NCBI. 2012; 10(37): 62-65.

[40] Lohakare S. Objectively structured clinical evaluation (OSCE) versus conventional examination method used for dental postgraduates students in practical. International Journal of Management, Information Technology and Engineering. 2015; 3(9): 23-30.

[41] Soni R, Rani S, Thokchom S, et al. A Comparative Study to assess the Opinion and Level of Satisfaction of the Student Nurses regarding Objective Structured Clinical Examination (OSCE) and Traditional Method of Clinical Skills Assessment related to Antenatal Examination. Int J Nurs Midwif Res. 2017; 4(2): 9-12. https ://doi.org/10.24321/2455.9318.201711

[42] Ameh N, Abdul M, Adesiyun G, et al. Objective structured clinical examination versus clinical examination an evaluation of students' perception and preference in a Nigerian Medical School. Niger Med Journal. 2014; 55(4): 310-313. PMid:25114366 https : //doi.org/10.4103/0300-1652.137191 